\title{
Penilaian Cepat Perubahan Lingkungan \\ Pasca Kejadian Bencana dengan Wahana Udara Tanpa Awak
}

\author{
Catur Aries Rokhmana \\ Jurusan Teknik Geodesi, Fakultas Teknik - Universitas Gadjah Mada \\ J1. Grafika No. 2, Yogyakarta 55281 \\ Email : caris@ugm.ac.id,website: www.potretudara.com
}

\begin{abstract}
Abstrak
Kombinasi kondisi wilayah Indonesia yang berbentuk kepulauan, infrastruktur yang terbatas, kekayaan sumber daya alam, dan kerawanan bencana merupakan tantangan bagi kegiatan penilaian lingkungan. Saat ini, penilaian kawasan dengan teknologi penginderaan jauh (inderaja) masih menjadi pilihan yang efisien. Sehingga perlu dibangun sistem inderaja yang mandiri dengan karakteristik yang sesuai dengan kondisi Indonesia. Riset ini bertujuan untuk menguji sistem inderaja dengan wahana udara tanpa awak (WUTA) untuk penilaian secara cepat perubahan lingkungan pasca kejadian bencana. Fokus penilaian secara cepat dimaksudkan untuk aplikasi respon terhadap kejadian bencana (tahap tanggap darurat), dan melihat perubahan aset obyek buatan manusia.. Citra yang dihasilkan juga harus memiliki resolusi spasial yang tajam $(<25 \mathrm{~cm})$ agar mudah menilai obyek buatan manusia. Riset ini telah dicobakan dalam melihat perubahan lingkungan pasca kejadian bencana erupsi Gunung Merapi, dan Bencana Gempa Bumi di Aceh Tengah. Pengalaman dari kedua kasus tersebut menunjukkan bahwa sistem inderaja memanfaatkan WUTA memiliki karakteristik biaya operasional rendah, mudah dijalankan oleh operator lokal, kecepatan perolehan hasil, akurasi yang memadai, dan efektif untuk luasan lebih kecil $5000 \mathrm{Ha}$.
\end{abstract}

Kata Kunci : penginderaan jauh, wahana udara tanpa awak, penilaian kawasan

\section{PENDAHULUAN}

Sejumlah fakta dan kondisi yang menjadi latar belakang kegiatan riset ini adalah:

1. Dalam suatu kejadian bencana, teknologi penginderaan jauh (inderaja) berperan sebagai penyedia informasi dasar bagi tahap mitigasi, tanggap darurat, dan rekonstruksi untuk tujuan penilaian kawasan/lingkungan. Karakteristik yang menonjol adalah kebutuhan kecepatan dalam penilaian lingkungan. Di lain pihak, umumnya wilayah terparah dalam kejadian bencana relatif kecil $(<5000 \mathrm{Ha})$. Obyek yang sering dinilai umumnya obyek buatan manusia seperti bangunan, utilitas kota, dan infrastruktur pendukung lainnya. Sehingga diperlukan citra yang mampu merekam obyek tersebut dengan jelas terlihat secara visual dengan resolusi spasial $<25 \mathrm{~cm}$. Sampai saat ini citra satelit komersial belum mencapai resolusi spasial setinggi foto udara. Jadi diperlukan sistem yang dapat memberikan data citra dengan resolusi spasial lebih tajam, efisien bekerja pada luasan sempit, dan biaya yang tidak berbeda jauh dengan keberadaan citra satelit selama ini. 
2. Sejumlah kawasan yang kaya sumber daya memerlukan kegiatan penilaian lingkungan dengan citra yang lebih tajam. Pada kasus di bidang pertanian, perkebunan, dan kehutanan, citra dari satelit selama ini tidak bisa melihat individu pohon. Sedangkan pada banyak kasus di perkebunan, diperlukan informasi individu pohon untuk penilaian potensi dan kesehatan. Kasus sumber daya di hutan merupakan kasus penilaian yang sulit dipecahkan. Sehingga apabila berhasil dalam mengaplikasikan teknologi Inderaja di kawasan hutan, maka untuk kawasan lainnya seperti pertambangan, perkebunan, dan sejenisnya juga akan dapat diterapkan.

3. Berdasarkan data dari Badan Pertanahan Nasional (2009), dari wilayah daratan Indonesia yang

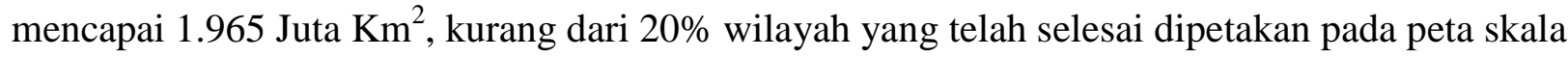
besar (lebih besar dari 1 : 2.500). Maka saat ini telah digunakan sejumlah citra satelit resolusi tinggi untuk mempercepat produksi Peta Dasar Pendaftaran Tanah. Jadi saat ini, Indonesia menjadi pasar dan pembeli jasa teknologi inderaja dari luar negeri yang cukup besar.

Menimbang sejumlah fakta tersebut, maka sejak tahun 2003 telah dilakukan upaya untuk membangun sistem inderaja yang sesuai dengan kebutuhan (Clark. et.al, 2010; Niethammer. et.al, 2010; Rokhmana, 2009; dan Rokhmana, 2010).

Tujuan dari kegiatan riset ini adalah membangun sistem inderaja dengan wahana udara tanpa awak (WUTA) untuk penilaian secara cepat kawasan pasca kejadian bencana dan penilaian aset sumberdaya alam. Ilustrasi dari kemampuan sistem inderaja ini adalah sebagai berikut:

Pasca kejadian bencana, sistem ini dapat dibawa oleh 1 tim secara backpack atau portable. Kemudian platform WUTA diterbangkan dengan dilempar tangan (hand-launch takeoff) untuk terbang selama 20 menit pada ketinggian di atas 350m di atas tanah guna merekam citra kawasan seluas $250 \mathrm{Ha}$ dalam sekali terbang. Selanjutnya, WUTA akan mendarat kembali secara otomatis untuk proses pengunduhan data citra. Citra diproses saat itu juga di lapangan untuk menghasilkan citra mosaik orthogonal dan data digital surface model (DSM) beberapa jam setelah proses pengunduhan. Kedua data tersebut adalah produk dasar yang dihasilkan untuk selanjutnya digunakan sebagai data dasar dalam interpretasi citra secara visual untuk mengekstrak informasi tematik.

Selanjutnya tulisan ini akan memberikan dua contoh kasus pemanfaatan WUTA sebagai sistem inderaja dalam penilaian cepat perubahan kawasan pasca kejadian bencana. Kedua kasus tersebut 
adalah wilayah Kali Code pasca kejadian bencana erupsi Merapi, dan wilayah Aceh Tengah pasca kejadian bencana gempa bumi.

\section{Arsitektur Sistem dan Kemampuan Sistem Inderaja menggunakan WUTA}

Seperti halnya sistem inderaja pada umumnya, maka pemanfaatan WUTA sebagai sistem inderaja juga terdiri dari bagian instrumentasi dan personalia sebagai operatornya. Satu tim WUTA terdiri dari personil yang bertugas sebagai: (1) Pilot pengendali wahana, (2) Navigator perancang jalur terbang; dan (3) Personil pemrosesan data (data handling). Sedangkan bagian instrumentasi terdiri dari: (1) Pesawat Aeromodeling yang membawa sensor kamera; (2) Sistem avionic untuk keperluan AutoPilot; (3) dan perangkat notebook untuk ground station dan pemrosesan data. Semua instrumentasi dapat diperoleh secara mudah di toko elektronik dan hobi aeromodeling (lihat Tabel 1.). Gambar 1 menunjukkan diagram alir proses produksi sistem inderaja.

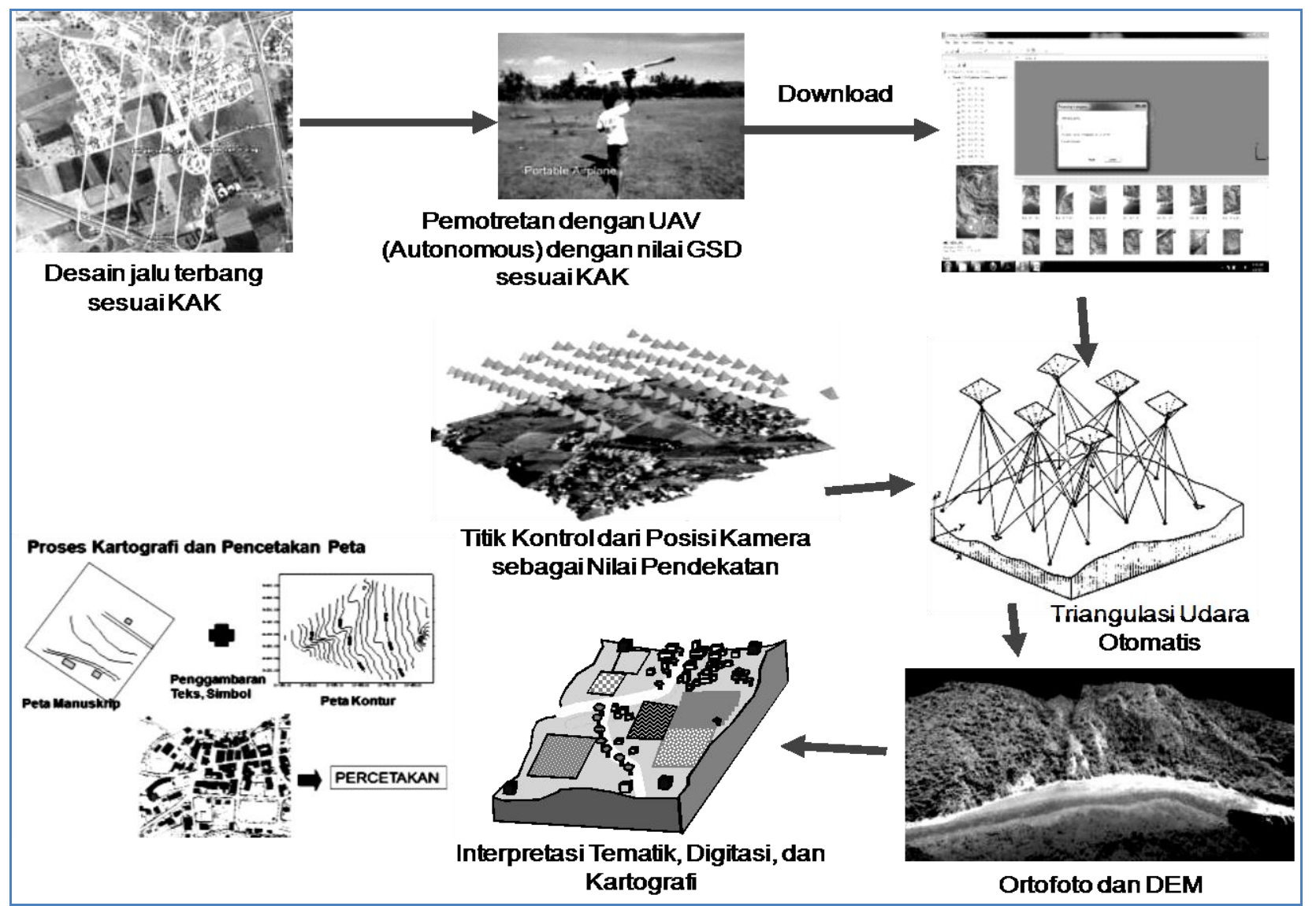

Gambar 1. Proses produksi sistem Inderaja memanfaatkan WUTA. 
Tabel 1. Perangkat instrumentasi Sistem Inderaja dengan WUTA

\begin{tabular}{|c|c|}
\hline Type Platform & $\begin{array}{l}\text { - Type Flying wing, or High-Wing } \\
\text { - Portable Backpack less than } 2.5 \mathrm{~kg} \\
\text { - Take-Off (Hand Launch) } \\
\text { - Landing: net landing or parachute drop } \\
\text { - Power: Motor electric brushless } \\
\text { - Flight Speed: } 60 \text { - } 70 \mathrm{~km} / \mathrm{h} \\
\text { - Flying High: } 200 \mathrm{~m} \text { - 400m } \\
\text { - Flight Time: < 30min. for electric }\end{array}$ \\
\hline $\begin{array}{l}\text { Avionic System } \\
\text { Less than }<700 \text { gr }\end{array}$ & $\begin{array}{l}\text { Autopilot System (open source: Ardupilot Mega) } \\
\text { - R/C min. } 9 \mathrm{CH} \text { with booster (1 Watt) range up to } 20 \mathrm{~km} \\
\text { - RF Modem for data telemetry (900MHz or } 2.4 \mathrm{GHz} 1 \mathrm{Watt}) \\
\text { Up to 40km range } \\
\text { - Microcontroller embedded IMU } \\
\text { - GPS receiver } 10 \mathrm{~Hz} \\
\text { - Optional FPV (First Person Video) piloting with } \\
\text { Video Sender (2.4Ghz or 5.8 Ghz1Watt) and } \\
\text { Micro Camera (<50gr) }\end{array}$ \\
\hline $\begin{array}{l}\text { Imaging Sensor } \\
\text { Less than < 300gr }\end{array}$ & $\begin{array}{l}\text { - Point and Shoot Digital Camera 12-14 MPix, field of view }>65 \mathrm{deg} \\
\text { Canon S100 with GPS Tag Enabled } \\
\text { - Mounting and anti-vibration system with Foam }\end{array}$ \\
\hline $\begin{array}{l}\text { Portable Ground } \\
\text { Station (Laptop and } \\
\text { Booster Antenna) }\end{array}$ & $\begin{array}{l}\text { - Mini LCD monitor 9”, } \\
\text { - Laptop or netbook } \\
\text { - Antenna more than } 8 \mathrm{dBi} \\
\text { - Antenna Tracking }\end{array}$ \\
\hline
\end{tabular}


Kemampuan produksi dasar dari sistem ini dapat dijelaskan sebagai berikut:

1. Sistem akan merekam foto udara dengan konfigurasi overlap $85 \%$ and sidelap $20 \%$. Hasil foto ini juga memiliki pandangan stereo untuk dapat mengekstrak informasi ketinggian obyek.

2. Resolusi spasial yang direkam umumnya $<25 \mathrm{~cm}$, sehingga cukup jelas untuk melihat obyek buatan manusia.

3. Kamera yang digunakan adalah jenis point and shoot (pocket camera) sehingga memiliki kualitas geometrik lensa yang rendah. Maka perlu dilakukan proses kalibrasi kamera agar dapat diperoleh kemampuan akurasi geometrik sub-meter $(<1 \mathrm{~m})$.

4. Problem utama dari perekaman udara adalah obyek yang tertutup obyek kain yang lebih tinggi seperti pepohonan. Jadi tidak semua obyek dapat dilihat dari rekaman udara.

\subsection{Citra foto udara VS Citra Satelit}

Saat ini citra satelit resolusi sangat tinggi seperti citra satelit IKONOS dan QUICKBIRD telah banyak diminta untuk keperluan studi lingkungan. Citra satelit memiliki kelemahan utama adanya liputan awan yang menghalangi pandangan obyek di bumi. Penggunaan foto udara dengan WUTA dapat mereduksi kebutuhan biaya, sebab WUTA dapat diaplikasikan dengan efisien pada luasan kecil $(<5.000 \mathrm{Ha})$. Tabel 2 mengilustrasikan perbandingan praktis antara citra satelit dengan citra foto udara.

Tabel 2. Perbandingan produk citra foto udara dan citra satelit

- Resolusi spasial citra satelit di pasaran Ikonos $(1 \mathrm{~m})$; Quickbird (0.6m); GeoEye $(0.45 \mathrm{~m})$; WorldView $(0.5 \mathrm{~m})$

- Resolusi spasial citra foto udara memanfaatkan WUTA $(5 \mathrm{~cm}-20 \mathrm{~cm})$

- Foto udara dari WUTA bebas awan, sebab terbang dibawah awan $(<300 \mathrm{~m})$

- Usia data WUTA lebih terkini, sebab dapat merekam foto (near-realtime) pada saat diperlukan

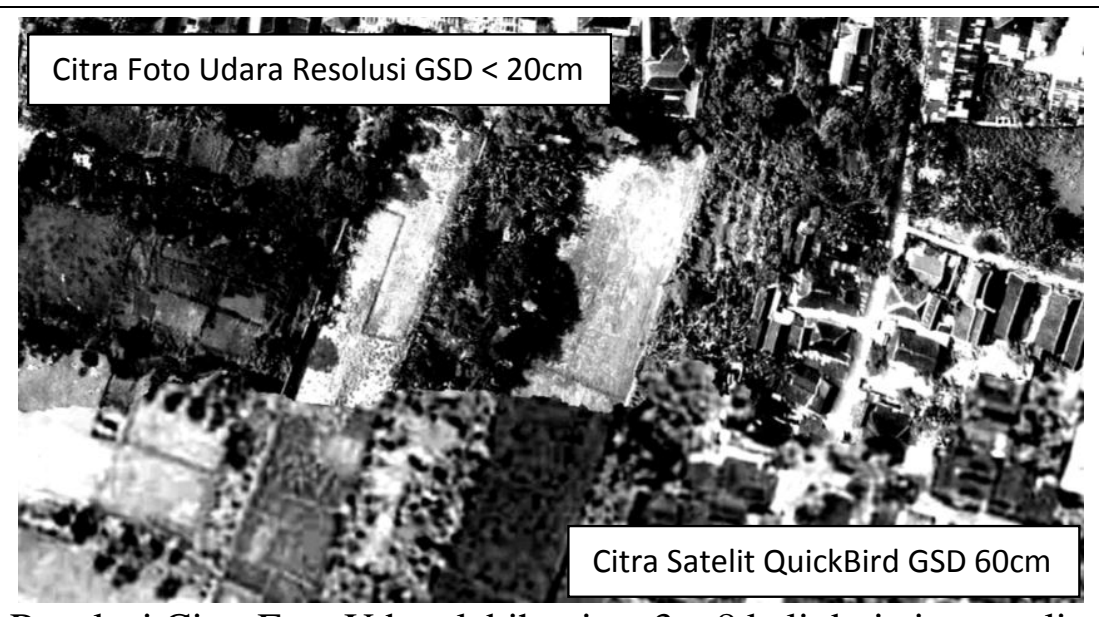

Resolusi Citra Foto Udara lebih tajam $3-8$ kali dari citra satelit 


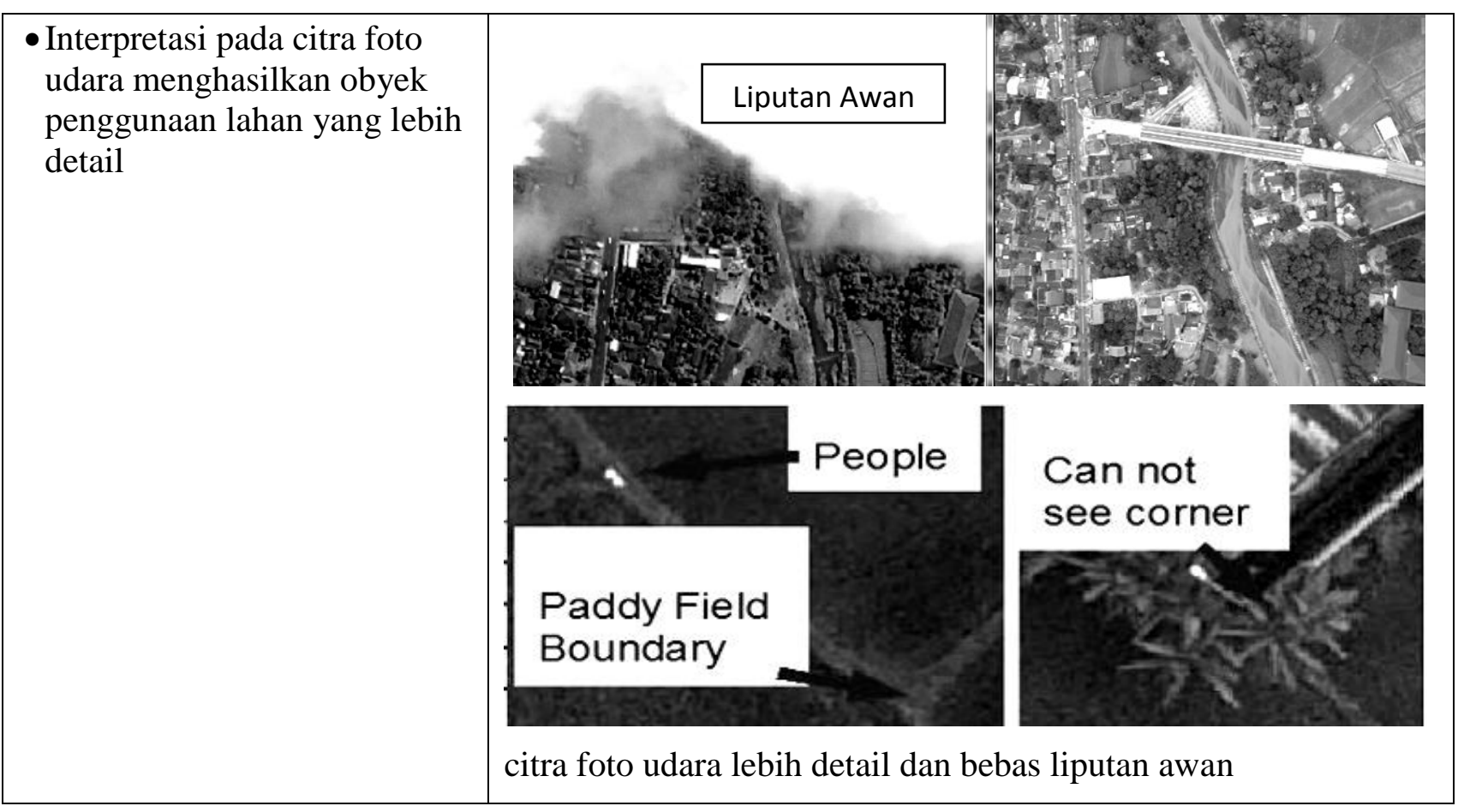

\section{Hasil dan Pembahasan}

\subsection{Kasus Pasca Bencana Erupsi Merapi}

Kasus ini berlokasi di kawasan Yogyakarta sepanjang Kali Code $(7 \mathrm{~km})$ dan di kawasan Sleman lokasi pembangunan Hunian Sementara (HUNTARA) Merapi. WUTA diterbangkan pada ketinggian 350m di atas tanah untuk merekam obyek sepanjang koridor Kali Code dan lingkungan sekitar Huntara. Gambar 2. memberikan ilustrasi informasi yang dapat dilihat. Beberapa diskusi yang bisa disampaikan adalah sebagai berikut:

1. Citra ortofoto hasil rekaman foto udara WUTA sangat jelas untuk melihat perubahan obyek alam dan buatan manusia dengan akurasi geometrik sub-meter $(<1 \mathrm{~m})$. Sejumlah obyek genangan lumpur tidak dapat terlihat di beberapa lokasi sebagai akibat dari padatnya bangunan yang terdapat disepanjang Kali Code. Obyek genangan lumpur tertutup oleh atap-atap bangunan yang cukup padat.

2. Keberadaan data rekaman sebelumnya (existing) sangatlah penting dalam hal studi untuk menilai perubahan lingkungan yang terjadi. Di masa mendatang perlu dikembangkan proses penilaian perubahan obyek (change detection) secara otomatis untuk mempercepat respon pada kejadian bencana. 
3. Proses produksi sistem inderaja dengan WUTA membutuhkan waktu 1 hari kerja lapangan untuk merekam koridor Kali Code sepanjang $7 \mathrm{~km}$. Waktu produksi ini cocok diterapkan dalam hal respon cepat pada masa tanggap darurat bencana.
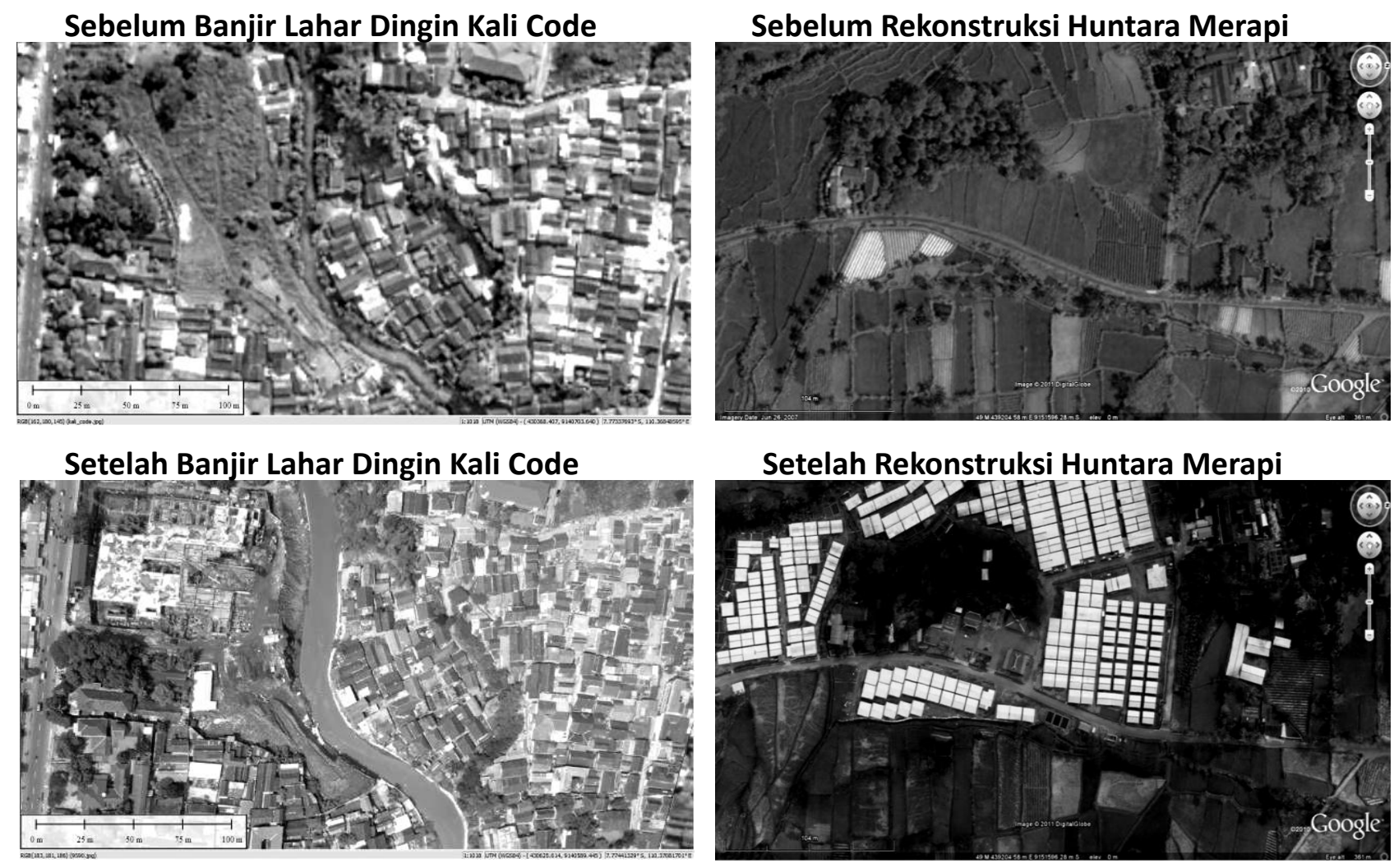

Gambar 2. Percobaan perekaman pasca kejadian bencana erupsi Gunung Merapi.

\subsection{Kasus Pasca Bencana Gempa Bumi di Aceh Tengah}

Kasus ini berlokasi di Aceh Tengah pasca kejadian gempa bumi 2013. Wilayah Aceh Tengah pada umumnya adalah daerah pegunungan. WUTA diterbangkan pada ketinggian 400m di atas tanah untuk merekam obyek di sebelas lokasi perkampungan yang terpisah-pisah. Luasnya wilayah penyebaran dampak bencana gempa bumi ini menyebabkan pendataan konvensional dengan mendatangi obyek diwilayah bencana menjadi lama. Maka penggunaan teknik inderaja akan sangat membantu dalam percepatan penilaian perubahan lingkungan. Gambar 3 memberikan ilustrasi hasil kegiatan perekaman data di Aceh Tengah. Beberapa diskusi aspek praktis yang bisa disampaikan adalah sebagai berikut:

1. Citra ortofoto hasil rekaman foto udara WUTA sangat jelas untuk melihat sejumlah rumah dan utilitas kota dalam kategori rusak parah (bangunan ambruk). Secara visual obyek yang rusak 
parah ditandai dengan keberadaan puing-puing bangunan. Tetapi sejumlah bangunan yang rusak sedang (retak) tidak dapat terlihat dari udara, sebab tidak terlihat adanya puing bangunan rusak. Maka survei darat masih diperlukan untuk mendata obyek dengan kategori rusak sedang.

2. Rekaman dari udara dapat diproses untuk menghasilkan model 3D kawasan pasca bencana. Sejumlah obyek yang longsor dapat terlihat jelas dalam model 3D (lihat Gambar 3).

3. Terbang di wilayah pegunungan yang cukup banyak turbulensi udara menyebabkan WUTA tidak selalu dapat terbang sesuai dengan jalur rencana, maka diperlukan penyesuaian di lapangan berdasarkan arah angin agar WUTA dapat terbang sesuai dengan rencana terbang.
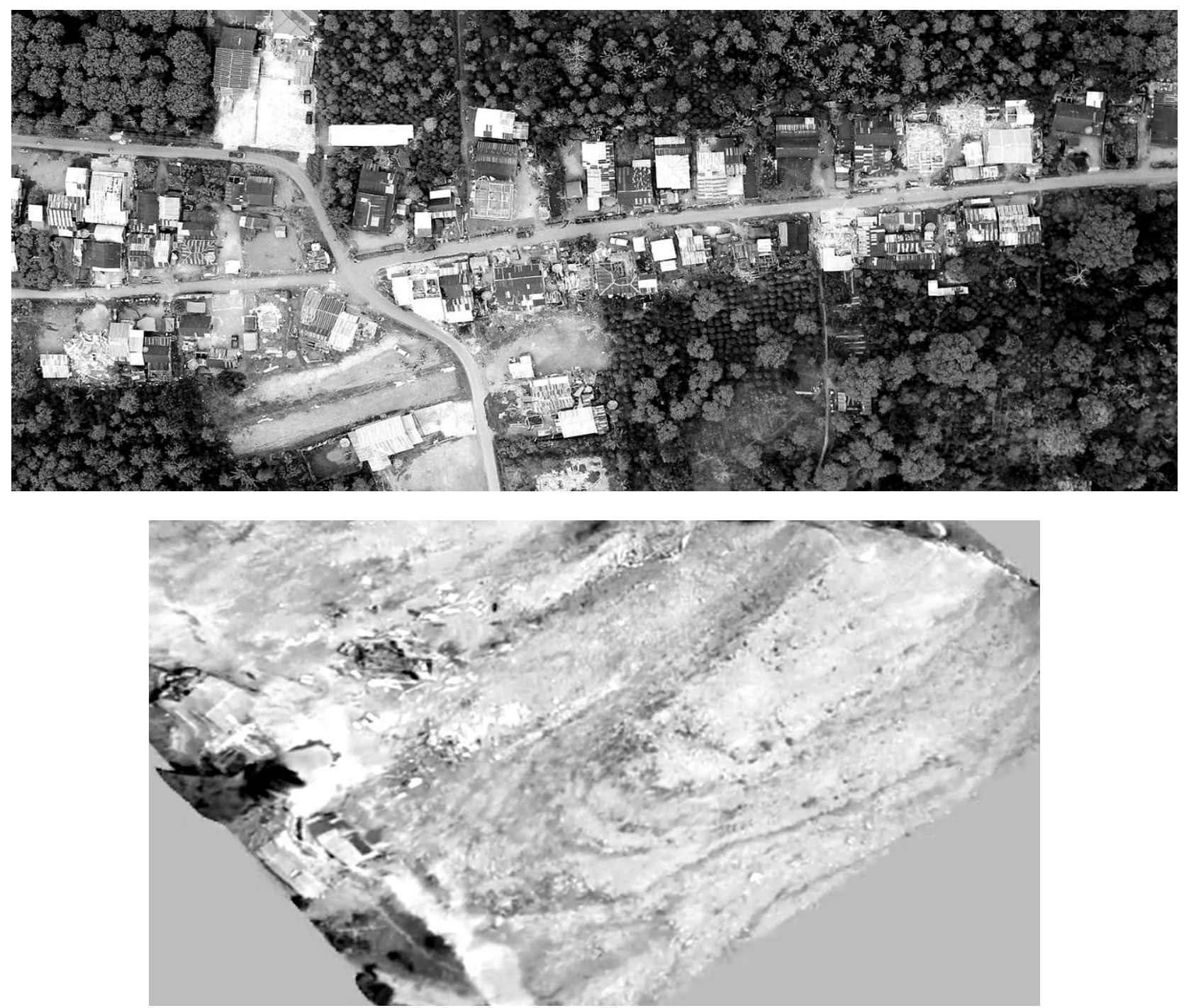

Gambar 3. Hasil perekaman dari udara sejumlah obyek Pasca Gempa di Aceh Tengah dan model 3D kawasan yang logsor. 


\section{Kesimpulan}

Tulisan ini telah menunjukkan dua kasus pengalaman lapangan dalam pemanfaatan sistem Inderaja dengan Wahana Udara Tanpa Awak untuk keperluan penilaian perubahan lingkungan secara cepat. Hasil rekaman WUTA dengan resolusi spasial $<25 \mathrm{~cm}$ dapat melihat obyek buatan manusia dan perubahannya secara jelas. Keberadaan data sebelumnya (existing) sangat penting dalam hal menilai perubahan yang terjadi. Tidak semua obyek dapat terlihat dari udara sebagai akibat sebagian obyek tertutup oleh obyek yang lebih tinggi. Bangunan dengan kondiri rusak sedang (retak) juga tidak dapat diinterpretasi dengan jelas pada citra foto udara. Di masa mendatang perlu dikembangkan proses otomatisasi dalam hal penilaian perubahan obyek (change detection) untuk mempercepat proses penilai perubangan lingkungan yang terjadi.

\section{DAFTAR PUSTAKA}

Clark, A.F., J. C., Woods and O. Oechsle, 2010, A Low-Cost Airborne Platform for Ecological Monitoring, International Archives of Photogrammetry, Remote Sensing and Spatial Information Sciences, Vol. XXXVIII, Part 5, Commission V Symposium, Newcastle upon Tyne, UK

Niethammer, U., S. Rothmund, M. R. James , J. Travelletti , M. Joswig, 2010, UAV-Based Remote Sensing Of Landslides, International Archives of Photogrammetry, Remote Sensing and Spatial Information Sciences, Vol. XXXVIII, Part 5, Commission V Symposium, Newcastle upon Tyne, UK

Rokhmana, C.A., 2009, The Potential Applications Of Balloon Photogrammetry For Cadastre Mapping, Proceeding SEASC, Bali

Rokhmana, C. A., 2010, Some Notes on Using Balloon Photogrammetry for the Precise Plantation, Proceedings FIG Congress 2010, Sydney, Australia, 11-16 April 2010 